\title{
Elaborando uma Cartilha Sobre as Ambiguidades da Violência Conjugal
}

The Formulation of a Brochure About the Ambiguities of Marital Violence

Desarollando un Folleto Sobre las Ambigüedades de la Violencia Conyugal

Kátia Lenz-de-Oliveira Universidade Federal do Amazonas

Maira Mendes dos Santos Governo do Estado do Amazonas

Simone Albuquerque de Moura Instituto Federal de Educação, Ciência e Tecnologia do Estado de Roraima

Wiulla Inácia Garcia Universidade Federal do Amazonas

Romeu Gomes Fundação Oswaldo Cruz

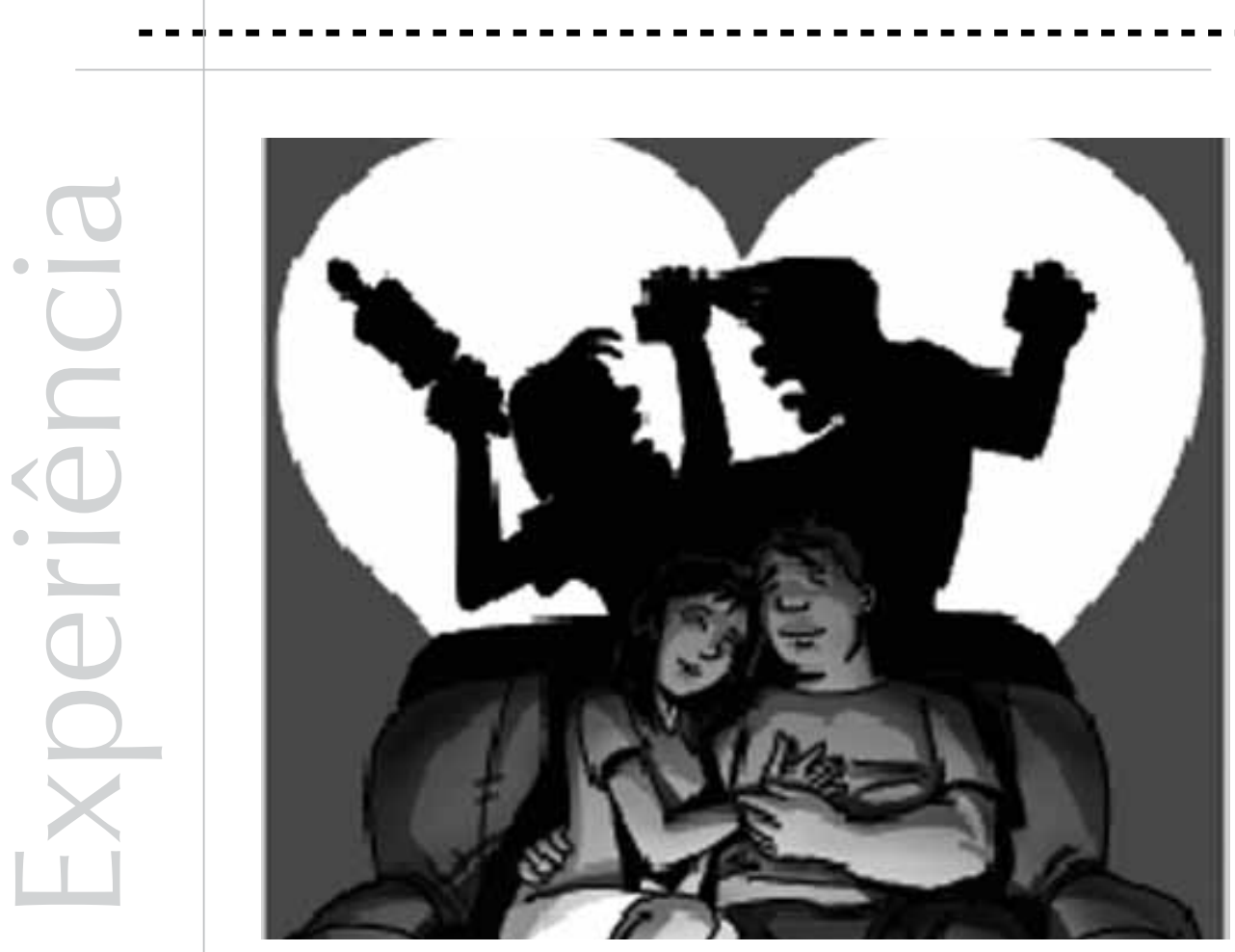


Resumo: O texto é um relato de experiência em um projeto de extensão universitária que elaborou e testou junto a grupos comunitários uma cartilha sobre violência conjugal direcionada tanto a mulheres quanto a homens, tendo como proposta construir uma comunicação que explicitasse e avaliasse os diferentes sentimentos e crenças relacionados ao tema, e ainda que respeitasse as possibilidades e os desejos de cada leitor. A abordagem de intervenção comunitária foi ancorada no construcionismo social. O tema da violência conjugal foi apresentado na cartilha tendo por base um esforço para articular as contribuições advindas tanto dos movimentos feministas como de outros estudiosos, mantendo a politização do tema. O processo de produção da cartilha é relatado buscando refletir sobre as dificuldades e as mudanças vivenciadas diante dos textos sobre o tema, dos testes do primeiro esboço junto a grupos comunitários, dos consultores e de feministas, de forma a apontar o fato de nossa atenção ter se concentrado em quatro categorias de análise do problema: dominação masculina, diversidade, amor romântico e ambigüidades, sendo a última a que nos pareceu ser mais amplamente debatida e apreendida por qualquer vertente de discussão diante do tema, embora todas sejam imprescindíveis. Por fim, apontamos nossa avaliação sobre os limites e os potenciais da última versão da cartilha.

Palavras-chave: Violência na família. Conflito conjugal. Gênero. Educação e igualdade. Construcionismo social.

Abstract:This paper is the experience account of a college extension project that elaborated and tested a brochure about marital violence with community groups directed to both women and men. Its purpose is to build a means of communication that explains and evaluates the different feelings and beliefs related to the issue, respecting the possibilities and wishes of each reader. The community intervention's approach was anchored on social construccionism. The issue of domestic violence was presented in the brochure, based on an effort to link both the contributions from feminist movements as from other researchers, maintaining the politicization of the issue. The brochure's production process is reported in an attempt to reflect about the difficulties and changes experienced in face of the texts about the subject, the first tests of the brochure with community groups, consultants and feminists. This work focused four categories of the problem analysis: male domination, diversity, romantic love and ambiguity. The last category seemed to have been widely discussed and understood by any aspect of the discussions on this subject, however all these themes are essential. Finally, we conclude our evaluation about the limits and the potential aspects of the last brochure's version.

Keywords: Family violence. Marital conflict. Gender. Educational equalization. Social construccionism.

Resumen: El texto es un relato de la experiencia en un proyecto de extensión universitaria que ha elaborado y testado junto a grupos comunitarios un folleto sobre violencia conyugal direccionada tanto a mujeres como a hombres, con la propuesta de construir una comunicación que tornarse explícitos y evaluase los diferentes sentimientos y deseos de cada lector. El abordaje de intervención comunitaria fue ancorado en el construcionismo social. El tema de la violencia conyugal fue presentado en el folleto y tuve como base el esfuerzo para articular contribuciones tanto de los movimientos feministas como de otros estudiosos, manteniendo la politización del tema. El proceso de producción del folleto es relatado buscando refletar sobre dificultades y cambios vividos, adelante de textos sobre el tema, de los testes del primer esbozo junto a grupos comunitarios, de los consultores y de feministas; de forma a apuntar que nuestra atención se ha concentrado en cuatro categorías de analice del problema: dominación masculina, diversidad, amor romántico e ambigüedades, siendo la última la que nos cayó ser ampliamente debatida y aprehendida por cualquier vertiente de discusión del tema, aunque todas sean imprescindibles. Por fin, apuntamos nuestra evaluación sobre los límites y potencias de la última versión del mismo.

Palabras clave: violencia contra la mujer; violencia conyugal, educación y equidad, materiales educativos, construcionismo social.

O trabalho foi realizado entre 2004 e 2006, em equipe com 15 alunos de Psicologia da Universidade Federal do Amazonas, com o objetivo de elaborar, mediante discussões com a população e com especialistas da Academia brasileira, uma cartilha sobre a violência contra a mulher e sobre a violência conjugal direcionada a homens e a mulheres, e também com o objetivo de construir uma comunicação que explicitasse e avaliasse os diferentes e ambíguos sentimentos e crenças relacionados ao tema, respeitando as possibilidades e os desejos de cada leitor. O título da cartilha é Violência no casal: o 
que você tem a ver com isso? (Universidade Federal do Amazonas, 2007).

Nesse texto, pretendemos apresentar nossa forma de pensar e discutir a problemática da violência conjugal e contra a mulher, que, com o texto da própria cartilha, é o principal resultado da intervenção relatado aqui. Acreditamos que nosso posicionamento e os conteúdos temáticos escolhidos contribuem para que o tema seja visto de forma mais polissêmica e para que seja mantido o tom politizado que os movimentos feministas vêm dando ao mesmo.

\section{Nosso entendimento sobre violência conjugal e contra a mulher}

O tema da violência contra a mulher e conjugal tem sido tratado basicamente de duas formas quase antagônicas no mundo ocidental e também no Brasil (Grossi, 2008; Soares, 1999). Existe um polo hegemônico sustentado pelos movimentos feministas, que iniciaram as denúncias públicas e, no Brasil, ainda incentivaram o setor público a criar Delegacias da Mulher e abrigos para mulheres- vítimas, sustentando que a violência contra a mulher é um ato relacionado diretamente à "dominação masculina" (expressão de Bordieu, 1999). Em contraposição, há um outro polo de discussão da problemática - que inclui feministas e outros grupos distantes desse movimento - que adverte quanto aos problemas do discurso da vitimização, aponta violências recíprocas entre homens e mulheres e usa conceitos como sistema familiar, sendo que alguns resvalam ainda para o conceito de masoquismo feminino. Procurando seguir a tendência dos estudos mais recentes, a de articular, dentro do possível, essas duas vertentes, passamos a tentar usar o potencial político e explicativo de cada uma delas.

Iniciaremos as apresentações pelas primeiras e produtivas explicações das feministas clássicas. Elas construíram e apropriaram-se de teorias que reformularam o olhar sobre a violência contra a mulher, criticando principalmente as abordagens que percebem a violência doméstica como um desvio psicopatológico individual.

A questão central tornou-se primeiramente tentar entender porque a mulher permanece por anos na relação violenta. A primeira resposta remete a questões de ordem social que dizem respeito a comportamentos-padrão das vítimas e a atitudes da comunidade de não se envolver ou de culpar a mulher. A segunda se refere a uma patologia desenvolvida como efeito das situações traumáticas, como resultado da pedagogia da violência, que Walter (1979, citado por Soares, 1999) chama de síndrome da mulher agredida, e tem como sintomas a baixa auto-estima, o medo, a depressão, a culpa e a passividade (Soares, 1999).

A pergunta sobre os homens era outra: por que eles batem? Mantendo a proposta básica que procura desvincular a violência contra a mulher dos indicadores patológicos, a resposta é que eles são apegados a visões estereotipadas sobre os papéis de gênero (Soares, 1998). Saffiotti e Almeida (1995) vão mais adiante, falando de síndrome do pequeno poder. Esta seria a reação masculina de colocar-se em um plano superior ao das mulheres com as quais convivem, de forma a compensar a sensação de impotência a que são submetidos nos outros tipos de ordenamento das relações sociais - em especial no eixo de classe social e de raça/ etnia -, ou para não perder a importância social que já alcançaram nos espaços públicos ou comunitários.

Nessa linha, as cientistas sociais feministas criam e desenvolvem, desde a década de 80, uma teoria de grande impacto que ajuda a analisar as várias problemáticas sociais, além da violência. É o conceito de gênero, que se refere à construção social do sexo, quando este fica restrito ao plano biológico, enquanto gênero diz respeito à forma como as culturas caracterizam o masculino e o feminino. "A 
idéia básica então é a de que há machos e fêmeas na espécie humana, mas a qualidade de ser homem e ser mulher é condição realizada na cultura" (Heilborn, 1996, p. 96). Esse conceito torna-se tão útil e frutífero que rompe as fronteiras do feminismo, expandindo-se em conceitos paralelos, e começa a ser usado por uma gama diversa de estudiosos, e divide o feminismo em diversas facções, fenômeno que atinge também as discussões sobre o tema da violência.

Os argumentos do polo de oposição à lógica de um feminismo mais embrionário se dão tanto em nível teórico como a partir de discussões quanto ao formato das intervenções.

A antropóloga Míriam Grossi (2008), embora declaradamente feminista, se posiciona como parte do segundo polo, na medida em que censura a tendência de caracterizar a masculinidade como violenta e diferencia entre agressão e violência. Grossi define a agressão como uma ação que permite revide, enquanto a violência não, sustentando que os atos denunciados como violência conjugal geralmente são agressões que podem partir de ambos os cônjuges. Esse é um fenômeno que está relacionado a gênero, mas que abrange um campo maior, a comunicação truncada entre o casal, em vez de relações de poder fixas que mantêm apenas um dos cônjuges no topo da hierarquia. Em 1998, ela já propunha que considerássemos a violência conjugal a partir do modelo conjugal moderno do Ocidente, baseado na idéia de amor. Essa nova categoria focaliza as contradições das vivências pós-modernas, pois o modelo conjugal calcado no amor romântico atual incita tanto a formulação de relações desiguais pautadas na complementaridade de gênero como relações igualitárias ligadas ao individualismo/psicologismo moderno.

Quanto às intervenções, as críticas ao primeiro polo giram principalmente em torno da noção de mulher como vítima passiva, focando o argumento que essa abordagem não considera o discurso da mulher como parte do problema.
Mendez (1995), psicoterapeuta de casais no Chile, reconhece os créditos da punição e de outras ações produzidas pelo feminismo no campo sociopolítico, como oferecer maior visibilidade para a violência contra a mulher e gerar condutas coerentes que facilitam o câmbio da cultura patriarcal, mas explicita o problema que vê no campo das psicoterapias. A explicação feminista destruiria a relação daqueles casais que querem mantê-la, deixaria o homem aprisionado na posição única de agressor e definiria a linha preventiva em função da assertividade (racionalidade) da vítima para desprender-se do homem violento. O objetivo principal da primeira sessão terapêutica sob sua responsabilidade "é que (os homens) venham a ser parte da verbalização: 'temos um difícil ou doloroso problema', e não 'tu tens um problema'" (p. 33).

Sara Cobb (1997), psicoterapeuta de uma casa-abrigo para mulheres vítimas nos Estados Unidos, avalia os dividendos das intervenções baseadas no discurso da vitimização:

\footnotetext{
Incapazes de escapar da força centrífuga de sua condição de vítima, (muitas mulheres, embora nem todas) regressam a seus abusadores com uma frequência assombrosa.... A não ser que possam construir-se a si mesmas como algo que não seja uma vítima..., (que possam) ocupar uma posição de agentes em suas vidas. (pp. 45-46)
}

Ela analisa ainda que entender sempre o homem agressor como louco ou mau anula a possibilidade de encará-lo como ser humano, o que produz uma sistemática desumanização do indivíduo e constitui o mesmo processo que alicerça um discurso violento.

Já a antropóloga brasileira filomena Gregori (1993), analisando os impasses das intervenções junto às mulheres vítimas no Brasil, na década de 80, afirma que essas intervenções, baseadas em dualidades em que um polo estava sempre associado à passividade e o outro à atividade de 
dominação - como ideologia x realidade, vítima $x$ algoz, feministas-ativas-conscientes $x$ mulheres-passivas-alienadas - não ofereciam espaço para as mulheres exporem outra forma de interpretar as situações que viviam ou a forma de ajuda que lhes era conveniente; ao contrário, havia uma imposição de valores que não permitia enxergar porque muitas mulheres, apesar da ajuda recebida, não conseguiam resolver seus problemas. Para solucionar o impasse, Gregori propõe considerarmos a existência de vários significados de violência nos diversos relacionamentos, e acrescenta que, "nesse movimento, não há lugar para (postularmos que existam) determinações imediatas e mecânicas do plano dos padrões (culturais) para o plano das condutas" individuais/ singulares (p. 130).

Os argumentos mais conciliatórios entre os polos partem de autores como os da antropóloga, também brasileira, Bárbara Soares (1999), que não condena à ineficácia o discurso baseado na vitimização feminina, defendendo o fato de que muitas mulheres dentro dos abrigos nos Estados Unidos têm se utilizado dele para mudar seu comportamento diante dos companheiros. Acrescenta um sobrenome àquele discurso, que é capaz de produzir a mudança, chamando de vitimização afirmativa o fruto positivo do programa de recuperação das vítimas de violência doméstica naqueles abrigos, uma solução original que começou a ser desenvolvida pelos Alcoólicos Anônimos desde 1930. Segundo ela, é um discurso autorreferente que tem como tema a culpa. Nela há primeiro o movimento de expor um contexto para mostrar que o narrador é isento de culpa, quando a auto-análise só demanda encontrar o próprio sofrimento. Só que a culpa, em vez de ser atribuída ao outro, é alocada na doença (alcoolismo - para alcoólatras; dependência psíquica do outro sob influência da cultura machista - para mulheres vítimas e homens agressores). Passase, então, a executar uma busca sobre o efeito da doença (alocada no passado) em seus comportamentos e percepções, e compor deliberações para reparar o mal que surge como consequência das atitudes anteriores; conjuga, por isso, uma ambiguidade entre passividade e atividade.

A mesma autora, embora mais tangencialmente, ainda abre no Brasil uma nova discussão teórica, propondo-nos um posicionamento que valide ambos os polos da polêmica, tomando em consideração a eficácia das intervenções de cada polo e a força argumentativa das teorias. Ela admite pensar que existem diferentes casos: um tipo bem representado pelas explicações feministas, na medida em que a violência se dá como um terrorismo do homem contra a mulher, e outros, nos quais podemos ver violências mútuas.

Atualmente, no Brasil, ainda temos Reichenheim et al. (2006) e Oliveira (2004) - dentre outros em nível internacional, como Casimiro (2008), de Portugal - que, seguindo os passos de Straus (1994, citado por Soares,1999), nos EUA, chegam a conclusões semelhantes. Eles diferenciam a convivência conjugal violenta em basicamente duas modalidades: uma em que haveria violências mútuas e moderadas, que Casimiro chama de violência comum no casal (termo que pode promover a noção de que essa violência é aceitável), e violência patriarcal ou de terrorismo do homem (desenvolvida em escalada e mais grave). A primeira autora desse artigo (Oliveira, 2004) fala em dinâmicas conjugais violentas simétricas e assimétricas.

É com essa forma de articulação entre os polos que começamos a compor a cartilha. Para nós, as palavras-chave de uma boa discussão da problemática eram: dominação masculina, diversidade, amor romântico e ambiguidades, mas, como veremos mais adiante, esta última ainda iria ganhar maior centralidade diante de nós, na medida em que a víamos como capaz de ser usada por qualquer vertente de explicação da problemática. 


\section{Referencial teórico de intervenção comunitária}

O projeto ancorou-se majoritariamente no construcionismo social, que tem em Gergen (1997) um dos seus principais defensores. Para uma apresentação esquemática desse referencial, trazemos aqui Guba (1991, citado por Montero, 1996), que o classifica a partir de três recortes. Mediante discussões ontológicas, o autor considera o construcionismo relativista, na medida em que entende que a linguagem não reflete um mundo independente, ao contrário, o constrói a todo o momento. Gergen sustenta que as descrições do mundo são compreendidas como produto de trocas situadas historicamente entre as pessoas, prevalecendo ou não de acordo com processos sociais como comunicação, negociação, conflito ou retórica. Na dimensão epistemológica, o construcionismo seria transacional-subjetivista, entendendo que não há neutralidade na produção do conhecimento e que a relação investigadorinvestigado deve ser vista como uma entidade monista que intervém na aquisição do conhecimento. No nível metodológico, o referencial é hermenêutico-dialético, por interpretar os discursos e discutir suas interpretações com os informantes, sendo a meta obter um consenso mais rico e variado que as informações prévias.

A principal implicação da adoção desse referencial para o projeto foi considerar que os discursos sobre violência, mais que descreverem uma verdade, atuam na construção do fenômeno e das pessoas, orientando suas práticas no cotidiano.

Para compor intervenções, o foco do construcionismo recai sobre os significados que orientam a vida das pessoas, buscando desconstruir os discursos dominantes e dar voz àqueles que têm dificuldade de desenvolver recursos de poder. A relação interventores/ pessoa ou grupo comunitário direciona-se para a equalização, em que se busca uma coconstrução dos sentidos sobre o problema em discussão. O papel dos interventores, então, não é o de especialistas que dirigem a intervenção rumo a determinados significados, mas o de criar condições para o surgimento de conversas que gerem novos sentidos. Eles não detêm a verdade, mas trazem diversos modos de ser e de descrever o problema que, em um processo de colaboração recíproca, podem ser úteis para as pessoas e as comunidades com quem interagem (ver Rasera \& Japur, 2001).

Devido à parceria pretendida com perspectivas feministas, no projeto, esforçamo-nos ainda para assumir o paradigma da construção e da transformação crítica, de Montero (1996), que articula o construcionismo social às teorias marxistas. É uma tarefa complexa, e tentamos desempenhá-la enfatizando as relações de poder, desde o recorte econômico, profissional, étnico, etário, até gênero, bem como considerando a noção de ideologia como falseamento da realidade, a ser usada quando avaliássemos que fosse uma ferramenta útil para promover maior participação ou conscientização dos valores a que estamos todos submetidos.

\section{Atividades do projeto e mudanças da cartilha}

A metodologia do projeto como um todo constituiu-se de: 1) leitura e discussão com a equipe executora de textos sobre o assunto; 2) levantamento da diversidade de significados sobre a violência conjugal em Manaus, através de observações e atendimentos na Delegacia da Mulher e de conversas com homens em botequins; 3) montagem do primeiro esboço da cartilha, quando foi premente negociar conteúdos sobre o tema e reservar momentos para discutir relações de poder entre os membros da equipe; 3) testagem desse esboço, já ilustrado e impresso, em 
5 grupos comunitários em Manaus, com o apoio da Delegacia da Mulher, da Secretaria Municipal da Infância e Adolescência SEMINF, do Projeto Cidadão/Governo do Estado do Amazonas, da Agência para o Desenvolvimento Integrado e Sustentado ADEIS (ONG), Movimento Comunitário pela Cidadania - MOCOCl e da Igreja Evangélica Assembléia de Deus no bairro Parque das Nações; 3) elaboração do segundo esboço e encaminhamento por e-mail para especialistas nacionais no tema, para avaliação; 6) elaboração da versão final (e posteriormente da segunda edição), partindo das avaliações anteriores.

O processo de testagem do primeiro esboço nas comunidades merece detalhamento. Os grupos de discussão do esboço eram compostos de várias formas: só de homens que viviam relação conjugal violenta (um grupo que existia como parte de outro projeto de extensão na Delegacia da Mulher, também coordenado pela primeira autora deste artigo), aleatoriamente só de mulheres convidadas por uma associação de bairro (de classe popular) vinculada à ADEIS, de mães e pais que tinham seus filhos atendidos na SEMINF, de homens e mulheres da igreja e usuários do Projeto Cidadão e do $\mathrm{MOCOCl}$. O número de participantes variou entre 3 (na delegacia) até por volta de 15 a 30 . O número de encontros para cada grupo foi de um, sendo que, com dois grupos, tivemos dois encontros. Os grupos foram convidados pelas instituições de apoio, nem sempre tendo sido explicitado que se tratava de teste para uma cartilha, mas que o tema do encontro era violência conjugal. A metodologia planejada dos encontros seguiu basicamente este padrão: a) explicitar o objetivo principal de testar a cartilha e também de acolher as demandas via reflexões e encaminhamentos; b) estabelecer o contrato de que todos os do grupo pudessem ter direito a voz e respeito às diferenças; c) levantamento das questões mais importantes e difíceis sobre violência conjugal, e, a seguir, das respectivas soluções que conseguiam ver, anotando-as em um papel madeira à vista de todos; d) apresentação da cartilha (leitura conjunta), negociando-se se os comentários sobre ela seriam feitos ao final ou durante a leitura; e) levantamento das dúvidas, críticas e sugestões de mudança, relacionando-as, se possível, às questões iniciais levantadas; f) discussão dos tópicos que a cartilha não estava discutindo, mas que interessavam ao grupo, para acolher sofrimentos e realizar encaminhamentos e g) avaliação do encontro, quando possível.

\section{Relação entre a equipe e o desenhista}

Avaliamos nossa relação com o desenhista como desconfortável, porque, tentando estabelecer uma dinâmica ganha/ganha, de construção conjunta, construímos com ele, inconscientemente, uma relação perde/ganha (hierarquizada), em que renunciávamos, em nome da manutenção dos serviços, a pontos essenciais. Nos encontros entre ele e a equipe (3 representantes), nós nos propúnhamos a expor nossas ideias e motivos. Ele parecia ouvir, mas seu primeiro desenho da capa foi contraproducente, porque incentivava o horror diante do tema. Era uma mulher desolada e só, tingida de vermelho e preto. Após novas e pacientes explicações sobre nossa postura diante do tema, enfim, surge uma capa que nos animou bastante, porque ele conseguira exprimir a ideia de ambiguidade melhor que a imagem que havíamos proposto. No entanto, ele se negava a mostrar os outros desenhos já feitos, afirmando que seria melhor fazê-lo apenas quando tudo estivesse concluído. Outros desenhos apresentados posteriormente também tiveram grande contribuição pessoal de sua parte. 


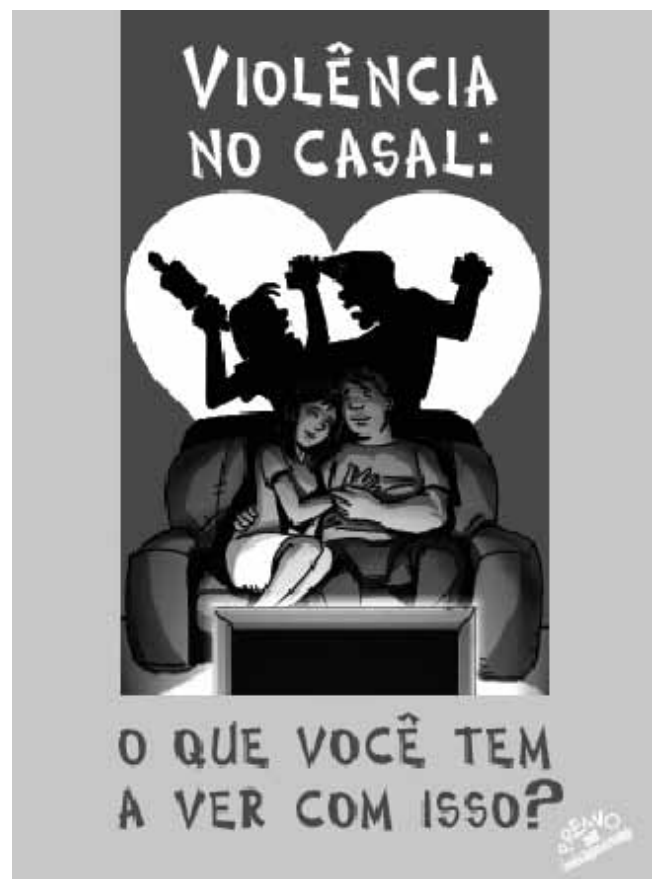

Figura 1: capa da cartilha.

Nos outros encontros, no entanto, ao comentarmos que não nos atendera ao desenhar pessoas muito bonitas e da mesma raça, ele se negou a fazer mudanças, dizendo ser trabalhoso refazer o desenho. Depois de muita discussão sobre ideologias hegemônicas, sustentou ainda saber o que mobilizava as massas, e pediu-nos para confiar na sua intuição artística. Nós? Renunciamos. Tínhamos receio de não conseguir outro desenhista experiente e disposto a tempo. Hoje pensamos que deveríamos ter estabelecido melhor, para nós mesmos, os critérios que definiriam até onde podemos ceder. Trabalhar com violência também significa empoderar-se para a defesa do que se acredita, embora mantendo abertos os canais de negociação.

\section{Testes do primeiro esboço da cartilha em grupos comunitários}

A cartilha em esboço, de 20 páginas, com 200 cópias impressas em preto e branco, continha os seguintes itens: Apresentação; $O$ que é violência?; O que faz com que alguém seja violento?; O que fazer para enfrentar a violência conjugal?; Serviços de atendimento especializado em Manaus; Grupos organizadas de combate à violência contra a mulher e/ou conjugal em Manaus e Indicação de livros para reflexão pessoal. Vale ressaltar que usamos o conceito de senso comum de que a violência ocorre quando causa danos em alguém (cf. Saffiotti \& Almeida, 1995), mas também o de Chauí (1984), que nos remete a pensar sobre os significados da violência mais difíceis de serem percebidos. No item O que faz com que alguém seja violento? elencamos frases populares sobre o tema e fizemos uma avaliação sobre suas implicações para a construção de identidades e posicionamentos.

Após 8 horas de treinamento com a equipe sobre construcionismo e metodologia dos testes do esboço, promovemos os encontros com os grupos comunitários, nos quais obtivemos poucas críticas. Ficava claro que a posição de psicóloga e/ou acadêmicos Ihes demandava muito mais o ímpeto de pedir conselhos que a atitude de participar da construção da cartilha. Tal fato nos leva a confirmar o quanto a população tem sido treinada a se submeter a profissionais de saúde que usam de uma postura tecnicista/positivista e verticalizada diante dos atendidos/educados, em uma visão mecanicista de comunicação (cf. Garnelo \& Langdon, 2005).

As críticas mais comuns foram relacionadas a palavras difíceis no texto, posteriormente substituídas. Uma delas, vinda do grupo da igreja, acompanhada de irritação, referiuse à falta de referências a Deus e à Bíblia, o que nos convocou a construir frases que dialogassem mais com o discurso religioso, como "se o agressor entender que se deixou levar erradamente por algo, pode conseguir tomar decisões por caminhos mais dignos, em nome do Bem, de Deus".

A técnica mais útil dos encontros foi a de pedir que contassem os pontos mais polêmicos e soluções diante do tema, antes de mostrarmos o esboço da cartilha. Marcante foi um encontro com um grupo só de mulheres, em que se puseram a condenar as mulheres vítimas, 
definindo-as como provocadoras diante de seus parceiros íntimos ou como incapazes de pensar, discurso esse contraposto por nós com ideias feministas, o que foi recebido por elas com atenção, mostrando que assim estavam ganhando maior conscientização sobre sua autossubjugação de gênero.

Nesse mesmo grupo, uma mulher se destacou ao relatar como conseguiu, sem apoio externo, desvencilhar-se de uma relação conjugal violenta. Impressionados, resolvemos pedir que ela (de pouca instrução) escrevesse sua história, planejando ver a possibilidade de distribuí-la na Delegacia da Mulher. Entusiasmada com a idéia de ajudar outras pessoas, ela aceitou. Com o texto escrito em mãos, pela manutenção da força e da simplicidade do relato oral, surgiu a ideia de incorporarmos o depoimento à cartilha.

Nesse caminho, pareceu-nos pertinente incluir também um depoimento masculino, tendo sido utilizada uma reportagem feita por um jornal local, que entrevistou um homem que havia frequentado o outro projeto de extensão articulado a este, o Grupo de apoio a homens vivendo relação conjugal violenta. Essas duas inclusões faziam a cartilha dar mais voz à população, tornando-a mais participante.

Em outro grupo, uma mulher contou que o desenho chamado de homem-diabo foi-lhe muito útil, porque se identificou como o diabo diante de seu companheiro, o que, aliado a sugestões de várias outras mulheres no sentido de responsabilizar as mulheres por seus atos, fez-nos incluir o desenho da mulher-diaba.

Um novo grande item foi acrescentado à cartilha: Por que o casal não se separa?, explorando a teoria do ciclo da violência, de Lenore Walker (1979, citado por Soares, 1999), e a metáfora da gangorra, proposta por Grossi (1998, 2008), para explicitar as alternâncias de poder entre o homem e a mulher e incluir teorias mais voltadas para a área da
Psicologia. Esse adendo se deu principalmente por termos percebido que - diante das falas das pessoas com as quais observávamos, atendíamos ou discutíamos o esboço da cartilha - tendíamos a discutir as situações focando dinâmicas (sobretudo) afetivas interpessoais e intrapessoais, e também por lembrarmos que, nas avaliações sobre uma série de oficinas educativas para homens jovens, desenvolvidas pelos Institutos Promundo e Papai, dentre outros, muitos grupos reivindicaram a inclusão do tema relacionamento de casal (Barker \& Nascimento, 2004, p. 81).

A definição do título da cartilha também se deu pela consulta à comunidade. Houve uma votação inicial da equipe, e prevaleceram dois títulos: Repensando a violência no casal e o escolhido pela maioria da comunidade: Violência no casal: o que você tem a ver com isso?, sugerido com o intuito de utilizar a ambiguidade do título e também de envolver a todos na temática.

\section{Principais críticas dos consultores à segunda versão e o uso que delas fizemos}

1) de não conceituarmos a violência estrutural, já que avaliamos que os exemplos de violência a traziam indiretamente, o que era suficiente. Temíamos tornar a cartilha muito teórica e entediante;

2) quanto à fisionomia da mulher desenhada, que a tornava distante das características típicas da mulher brasileira e amazonense, ao que concordamos, mas não modificamos, em função da relação difícil com o desenhista;

3) quanto ao desenho que mostra uma mulher varrendo e cuidando do bebê enquanto seu marido está vendo televisão, como exemplo de violência contra a mulher por dupla jornada de trabalho, o que achamos exagerado e preferimos não modificar; 
4) que faltavam exemplos de como combater a violência, o que foi usado abundantemente.

\section{Críticas à $1 \underline{a}$ edição e novas mudanças}

Após o lançamento, em novembro de 2006, a cartilha ainda recebeu críticas importantes, como a da Secretaria Especial de Políticas para as Mulheres, da Presidência da República, que alerta para o fato de que ela enuncia um conceito de gênero diferente dessa Secretaria, e de militantes amazonenses da União Brasileira de Mulheres, que afirmaram ver a culpabilização da mulher.

Julgamos que essas críticas se referiam especialmente às páginas que desenvolviam uma segunda resposta à pergunta Por que $O$ casal não se separa?, onde apresentamos a metáfora da gangorra. Com a ideia de fazer uma segunda edição com o patrocínio do Governo do Amazonas, em outubro de 2007, passamos a tentar oferecer uma versão que minimizasse essas últimas críticas. Os estudos de Machado e Magalhães (1998) foram muito úteis nesse sentido. As autoras, na articulação entre os estudos desconstrucionistas de gênero e a psicanálise lacaniana, concluem que os comportamentos agressivos das mulheres não são qualitativamente iguais aos dos homens em função de um contrato conjugal camuflado - no nível do impensado e criado a partir da cultura - que se sustenta a partir da noção de que cabe ao homem assegurar ou não a respeitabilidade da companheira. Para elas, os homens desenvolvem uma estrutura obsessiva que os incita à violência, uma ação que não permite revide ou resposta, enquanto as mulheres - a partir de uma estrutura histérica - cometem agressão, uma postura apta a reconhecer e a validar reações. Mantendo o desenho da gangorra, tais asserções foram incluídas na cartilha, mas desviamo-nos dos termos de psicopatologia, com o adendo de que podemos encontrar outros tipos de relação conjugal violenta, embora este nos pareça ser o majoritário.

Uma crítica rebatida se deu em relação à oração que serve de epígrafe, asseverando que a oração fugiria aos princípios feministas, que prezam pelo discurso laico. Nossa resposta é que escrevemos para a população em geral, que exibe um alto percentual de aderência a uma fé religiosa, e que termos religiosos podem servir como veículo de reflexão sobre atitudes éticas. Essa última assertiva se baseia em estudos, como os de Santose Ramon (2007), que revelam que as instituições religiosas conseguem difundir preceitos éticos - ajudando a formar pessoas mais conscientes de si e mais autoconfiantes, além de relacionamentos mais acolhedores com as outras pessoas e com a natureza - ao promover reflexões sobre questões existenciais, como a origem e o final da vida, os sentidos da existência, o bem e o mal. Além disso, a oração usada é mote dos Alcoólicos Anônimos, grupo que mais atinge eficiência e popularidade no combate às dependências químicas, problemática relacionada à violência, conforme Soares (1999).

Por fim, percebemos que valia a pena incluir um novo item, o de indicação de filmes. Era outra forma de incentivar discussões mais afetivas e personalizadas sobre o tema.

\section{Considerações finais}

Ao final do projeto, podemos dizer que nossas novas sínteses sobre o tema giravam em torno das mesmas categorias: dominação masculina, diversidade e amor romântico e ambiguidades, mas agora esta última podia ser melhor articulada com a primeira. Isso foi possível quando percebemos que os estudos de Machado (2001) e Machado e Magalhães (1998), podiam ser usados para falar da dimensão afetiva e ambígua das vivências conjugais, sem perder de vista a ainda forte e atuante cultura hierárquica de gênero.

Confirmou-se ainda a premência por manter intervenções diante do tema da violência conjugal que prime por relações em que todos os envolvidos - quer profissionais ou militantes interventores, quer população atendida ou que vá receber as informações que desejamos passar - sejam ativa e afetivamente 
participantes das discussões e das tomadas de decisão. A complexidade da cultura híbrida brasileira (cf. Carvalho, 2001; Heilborn,1996; Machado, 2001), da cultura pós-moderna (cf. Machado, 2001) e também do próprio tema em questão nos impõem ainda estabelecer e ensinar a compor posicionamentos de humildade diante de outros diferentes de nós, de co-contrução, e ainda de autorreflexões sobre nossos valores e lugar social.

É importante também reconhecer a principal limitação da cartilha: não conseguimos estabelecer uma linguagem tão popular quanto queríamos, o que pode torná-la mais voltada para as pessoas com maior grau de instrução ou que têm o hábito da leitura e/ou do pensamento lógico formal. Tal característica provavelmente surgiu devido à imponderada expansão do público-alvo, na medida em que tentamos contemplar as opiniões de estudiosos e entidades da área. Avaliamos agora que a melhor estratégia nessa outra direção seria investir na elaboração de produtos que possuam mais narrativas/ depoimentos - como o livro da FIOCRUZ Palavra de Homem (Lopes \& Giffin, 2001) -, mostrando especialmente formas de enfrentamento à problemática. Vale lembrar, como inovadores (porque voltado para homens) e também populares/narrativos, o vídeo Não é fácil, não, do Instituto Promundo
(Arruda, Nascimento, Barker, \& Bianco, 2003), e a revista Vista essa camisa: homens pelo fim da violência contra a mulher, do Instituto PAPAI (2006), em formato de telenovela.

Atualmente, percebemos também que poderíamos ter investido em traduções populares dos estudos de Brandão (2006), que explicita a diferente visão de mundo das classes populares em relação à das camadas médias/individualistas no que se refere a relações de gênero.

Por outro lado, parece-nos que a cartilha, tal qual se encontra, contempla os tópicos principais que surgiram tanto nas discussões comunitárias como nas discussões com os especialistas participantes, e já serve como desencadeadora de mudanças de perspectiva e de comportamento em prol de relações mais igualitárias e prazerosas entre pessoas que vivem relacionamentos conjugais conflituosos e do combate à dominação masculina.

Também percebemos que a grande utilidade da cartilha se dá diante de profissionais ou militantes que buscam conhecimento sobre o tema em uma tradução simples e esquemática, até porque muitos deles são carentes de teorias a respeito da violência conjugal; por isso, então, faz sentido publicar este artigo e divulgar a cartilha.

\section{Kátia Lenz-de-Oliveira}

Doutora em Saúde Coletiva, psicóloga e docente da Faculdade de Psicologia da Universidade Federal do

Amazonas, Manaus, AM - Brasil. E-mail: katialenz@ufam.edu.br

Maira Mendes dos Santos

Psicóloga, Assessora Técnica da Gerência de Atendimento Sócio-educativo do Governo do Estado do Amazonas, AM - Brasil. E-mail: maimendes@yahoo.com.br

\section{Simone Albuquerque de Moura}

Psicóloga do Instituto Federal de Educação, Ciência e Tecnologia do Estado de Roraima, Boa Vista, RR - Brasil. E-mail: simone.albuquerque@hotmail.com

Wiulla Inácia Garcia

Mestranda em Psicologia pela Universidade Federal do Amazonas, Manaus, AM - Brasil. Psicóloga do Tribunal de Justiça do Amazonas. E-mail: wiulla@hotmail.com

\section{Romeu Gomes}

Doutor em Saúde Pública, Pesquisador e docente da Pós-graduação do Instituto Fernandes Figueira - Fundação Oswaldo Cruz. E-mail: romeu@iff.fiocruz.br

\section{Endereço para envio de correspondência:}

Universidade Federal do Amazonas - Faculdade de Psicologia. Av. General Rodrigo Otávio Jordão Ramos, 3000 Setor Norte Campus Universitário - Coroado III - Manaus, AM - Brasil - CEP 69077-000. 


\section{Referências}

Arruda, S., Nascimento, M., Barker, G. (Produtores), \& Bianco, R. (Diretor). (2003). Não é fácil, não!: prevenindo a violência de homens contra as mulheres [filme-vídeo]. Rio de Janeiro: Instituto Promundo \& Instituto Noos.

Brandão, E. R. (2006). Renunciantes de direitos? A problemática do enfrentamento público da violência contra a mulher: o caso da Delegacia da Mulher. Physis, 16(2), 207-231.

Barker, G., \& Nascimento, M. (2004). Da violência à convivência (caderno 3). Rio de Janeiro: Instituto Promundo.

Bordieu, P. (1999). A dominação masculina. Rio de Janeiro: Bertrand Brasil.

Carvalho, J. M. (2001). Cidadania no Brasil: o longo caminho. Rio de Janeiro: Civilização Brasileira.

Casimiro, C. (2008). Violências na conjugalidade: a questão da simetria do gênero. Análise Social, 43(3), 579-601.

Chauí, M. S. (1984). Participando do debate sobre mulher e violência. In B. Franchetto, M. L. Cavalcanti \& M. L. Heiborn (Eds.), Perspectivas antropológicas da mulher 4 (pp. 23-62). Rio de Janeiro: Zahar.

Cobb, S. (1997). Dolor e pareja: la fuerza contrífuga de las narraciones de mujeres víctimas en un refugio para mujeres golpeadas. In M. Pakman (Ed), Construcciones de la experiencia humana (pp. 17-61). Barcelona: Gedisa.

Garnelo, L., \& Langdon, J. (2005). A antropologia e a reformulação das práticas sanitárias na atenção básica à saúde. In M. C. S. Minayo (Ed.), Críticas e atuantes: ciências sociais humanas na América Latina (pp. 133-156). Rio de Janeiro: FIOCRUZ

Gergen, K. J. (1997). Realities and relationships. Cambridge: Harvard University Press.

Gregori, M. F. (1993). Cenas e queixas. São Paulo: Paz e Terra.

Grossi, M. P. (1998). Rimando amor e dor. Reflexões sobre a violência no vínculo afetivo- conjugal. In J. M. Pedro \& M P. Grossi (Ed.), Masculino, feminino, plural (pp. 293-314) Florianópolis: Mulheres.

Grossi, M. P. (2008). Violência, gênero e sofrimento. In T. Rifiotis \& T. H. Rodrigues (Ed.), Educação e direitos humanos: discurso críticos e temas contemporâneos (pp. 121-134) Florianópolis: Ed. da UFSC.

Heilborn, M. L. (1996). Violência e mulher. In G. Velho \& M. Alvito (Ed.), Cidadania e violência (pp. 89-97). Rio de Janeiro: Ed. da UFRJ.

Instituto Papai (Produtor), \& Medrado, B. (Diretor). (2006). Vista essa camisa: homens pelo fim da violência contra a mulher [revista em quadrinhos]. Brasília, DF: Rede de Homens pela Eqüidade de Gênero (RHEG) , Comissão Temporária do Ano da Mulher Latino-Americana do Senado Federal.

Lopes, A. S., \& Giffin, K. (2001). Palavra de homem. Rio de Janeiro: NESC.
Machado, L. Z., \& Magalhães, M. T. B. (1998). Violência conjugal: os espelhos e as marcas/Série Antropologia 240. Brasília, DF: UnB. Recuperado em 6 de outubro de 2007, de http://www. unb.br/ics/dan/Serie240empdf.pdf

Machado, L. Z. (2001). Masculinidades e violências: gênero e malestar na sociedade contemporânea/ Série Antropologia 290. Brasília, DF: UnB. Recuperado em 6 de outubro de 2007, de http://www.unb.br/ics/dan/Serie290empdf.pdf

Mendez, C. L. (1995). Violencia en la pareja. In H. Maturana, F. Coddou, H. Montenegro, G. Kunstmann \& C. L. Mendez. Violencia en sus distintos ámbitos de expresión (pp. 23-38). Santiago de Chile: Dolmen.

Montero, M. (1996). Paradigmas, corrientes y tendencias de la psicología social finisecular. Psicologia \& Sociedade, 8(1), 103-109.

Oliveira, K. L. C. (2004). Quem tiver a garganta maior vai engolir o outro: sobre violências conjugais contemporâneas. São Paulo: Casa do Psicólogo.

Rasera, E. F., \& Japur, M. (2001) Contribuições do pensamento construcionista para o estudo da prática grupal. Psicologia: Reflexão e Crítica, 14(1), 201-209.

Reichenheim, M. E., Moraes, C. L., Szklo, A., Hasselmann, M. H., Souza, E. R., Lozana, J. A. et al. (2006). The magnitude of intimate partner violence in Brazil: Portraits from 15 capital cities and the Federal District. Cadernos de Saúde Pública, 22(2), 425-37.

Santos, E. A., Ramon, S. P. (2007). Religião e individuação: fenomenologia do desenvolvimento humano através da direção espiritual. Psico, 38(1), 85-93.

Soares, B. M. (1999). Mulheres invisíveis: violência conjugal e novas políticas de segurança. Rio de Janeiro: Civilização Brasileira.

Saffiotti, H. I. B., \& Almeida, S. S. (1995). Violência de gênero, poder e impotência. Rio de Janeiro: Revinter.

Universidade Federal do Amazonas - UFAM (Produtor), Oliveira, K. L. C., Santos, M., Moura, S., \& Garcia, W. (Diretores). (2007). Violência no casal: o que você tem a ver com isso? [cartilha popular]. Manaus: Universidade Federal do Amazonas - UFAM/Pro-Reitoria de Extensão e Interiorização/Governo do Estado do Amazonas. Recuperado em 05 de setembro de 2008, de http://www.ufam.edu.br/instituicao/pro_reitorias/ proext/producao.htm 